\title{
Exercise tests in Chagas cardiomyopathy: an overview of functional evaluation, prognostic significance, and current challenges
}

\author{
Henrique Silveira Costa ${ }^{[1],[2],}$ Márcia Maria Oliveira Lima ${ }^{[1],[2]}$, Pedro Henrique Scheidt Figueiredo ${ }^{[1],}$ \\ Vanessa Pereira Lima ${ }^{[1]}$, Matheus Ribeiro Ávila ${ }^{[1]}$, Kenia Kiefer Parreiras de Menezes ${ }^{[3]}$, \\ Vanessa Amaral Mendonça[1], Ana Cristina Rodrigues Lacerda ${ }^{[1]}$, Maria Carmo Pereira Nunes ${ }^{[2]}$, \\ Mauro Felippe Felix Mediano ${ }^{[4]}$ and Manoel Otávio da Costa Rocha ${ }^{[2]}$
}

\author{
[1]. Universidade Federal dos Vales do Jequitinhonha e Mucuri, Faculdade de Ciências Biológicas e da Saúde, \\ Departamento de Fisioterapia, Diamantina, MG, Brasil. \\ [2]. Universidade Federal de Minas Gerais, Escola de Medicina, \\ Curso de pós-graduação em Infectologia e Medicina Tropical, Belo Horizonte, MG, Brasil. \\ [3]. Universidade Federal de Minas Gerais, Escola de Educação Física, Fisioterapia e Terapia Ocupacional, \\ Curso de pós-graduação em Ciências da Reabilitação, Belo Horizonte, MG, Brasil. \\ [4]. Fundação Oswaldo Cruz, Instituto Nacional de Infectologia Evandro Chagas, Rio de Janeiro, RJ, Brasil.
}

\begin{abstract}
Patients with Chagas cardiomyopathy $(\mathrm{ChC})$ usually progress with fatigue and dyspnea. Exercise tests are valuable for the functional evaluation of these patients. However, information about the applicability of the exercise tests is scattered, and no studies have systematically reviewed the results. Thus, the present review explored the general aspects and prognostic value of exercise tests in patients with ChC. A literature search of the MEDLINE, Web of Science, CINAHL, Scopus, and LILACS databases was performed to identify relevant studies. There were no data restrictions, and articles that met the objective of the study were selected. Articles written in English, Portuguese, and Spanish were considered, and 25 articles were finally included. The peak oxygen uptake (VO2peak) was correlated with demographic and echocardiographic variables. Echocardiographic features of the left ventricular diastolic function and right ventricular systolic function appeared to be determinants of functional capacity, in addition to age and sex. VO2peak was associated with higher mortality, especially in patients with dilated $\mathrm{ChC}$. The minute ventilation/carbon dioxide production slope (VE/VCO2 slope) was a strong predictor of survival; however, more studies are needed to verify this observation. Field tests showed moderate to strong correlation with VO2peak and thus may be inexpensive tools for the functional evaluation of patients with ChC. However, few studies have verified their prognostic significance. While exercise tests are useful tools for functional assessment, information is scarce regarding further considerations, and many of the criteria are based on guidelines for other heart diseases.
\end{abstract}

Keywords: Chagas disease. Chagas cardiomyopathy. Exercise test. Exercise tolerance. Evaluation. Prognosis.

\section{INTRODUCTION}

Chagas disease remains a serious public health problem. While the incidence and prevalence are decreasing dramatically, 6 million people are infected in Latin America and more than 70 million are at a risk of infection ${ }^{1}$. In Brazil, Chagas disease is a major cause of morbidity and mortality among tropical diseases and

\footnotetext{
Corresponding author: Dr. Henrique Silveira Costa.

e-mail: henriquesilveira@yahoo.com.br

(D) https://orcid.org/0000-0002-1426-7246

Received 9 March 2020

Accepted 21 May 2020
}

accounts for approximately 7.5 times as many disability-adjusted life-years lost as malaria ${ }^{2}$. Among infected patients, 30-40\% develop a cardiac form of the disease ${ }^{3,4}$, with a wide spectrum of manifestations such as clinically nonapparent abnormalities, severe heart failure, thromboembolism, malignant arrhythmias, and sudden cardiac death ${ }^{5}$. A recent statement ${ }^{6}$ standardized the terms Chagas cardiomyopathy $(\mathrm{ChC})$ to define patients with cardiac involvement (electrocardiographic abnormality in patients with positive serological tests against Trypanosoma cruzi) and dilated $\mathrm{ChC}$ to describe patients with left ventricular enlargement with systolic dysfunction. However, patients with $\mathrm{ChC}$, regardless of systolic function and degree of ventricular dilation, have impaired functional capacity ${ }^{7}$, which reinforces the need for evaluation by exercise tests. 
Even in asymptomatic patients, non-invasive methods such as conventional maximal exercise test and cardiopulmonary exercise testing (CPET) can detect significant changes, including exerciseinduced ventricular arrhythmias (EIVAs) ${ }^{8}$ and chronotropic incompetence ${ }^{9}$. However, the usefulness of exercise tests in $\mathrm{ChC}$ has not been systematically discussed. This review explored the applicability of exercise tests in patients with $\mathrm{ChC}$, highlighting their general aspects, determinants, and prognostic value, as well as the challenges faced.

\section{SEARCH METHOD}

This comprehensive review aimed to verify the applicability and prognostic value of exercise tests for the functional evaluation of patients with ChC. Relevant studies were identified from searches of the Medical Literature Analysis and Retrieval System Online (MEDLINE), Web of Science, the Cumulative Index to Nursing and Allied Health Literature (CINAHL), Scopus, and Latin American \& Caribbean Health Sciences Literature (LILACS) databases using search terms related to $\mathrm{ChC}$, functional capacity, and exercise tests.

The eligibility criteria included studies that a) enrolled patients diagnosed with $\mathrm{ChC}$; b) evaluated functional capacity using CPET, conventional exercise tests, or field tests; and c) were written in the
English, Spanish, or Portuguese. We defined ChC with preserved left ventricular ejection fraction (LVEF) as those patients with positive serology for Trypanosoma cruzi, a normal ventricular function, and the presence of arrhythmias and/or conduction disorders. Patients with left ventricular systolic dysfunction and cardiac dilation were categorized as having dilated $\mathrm{ChC}^{10}$. The exclusion criteria were review studies, duplicate articles, animal studies, manuscripts that compared functional parameters to other heart conditions, articles that did not demonstrate the clinical presentation of $\mathrm{ChC}$, and articles that did not match the objective of the present review. Manuscripts without statistical analysis, as well as those with fewer than 10 individuals per group, were also excluded. There were no restrictions on the year of publication until January 2020. This review did not include comparisons of functional capacity between healthy individuals and patients with $\mathrm{ChC}$ as a recent systematic review and meta-analysis ${ }^{7}$ has already been performed.

The original search identified 634 articles. After reading the titles and abstracts of these articles to identify all terms related to functional evaluation by exercise tests, 69 were selected for fulltext review and 25 articles met the criteria for this investigation. Figure 1 outlines the flow of papers through the review.

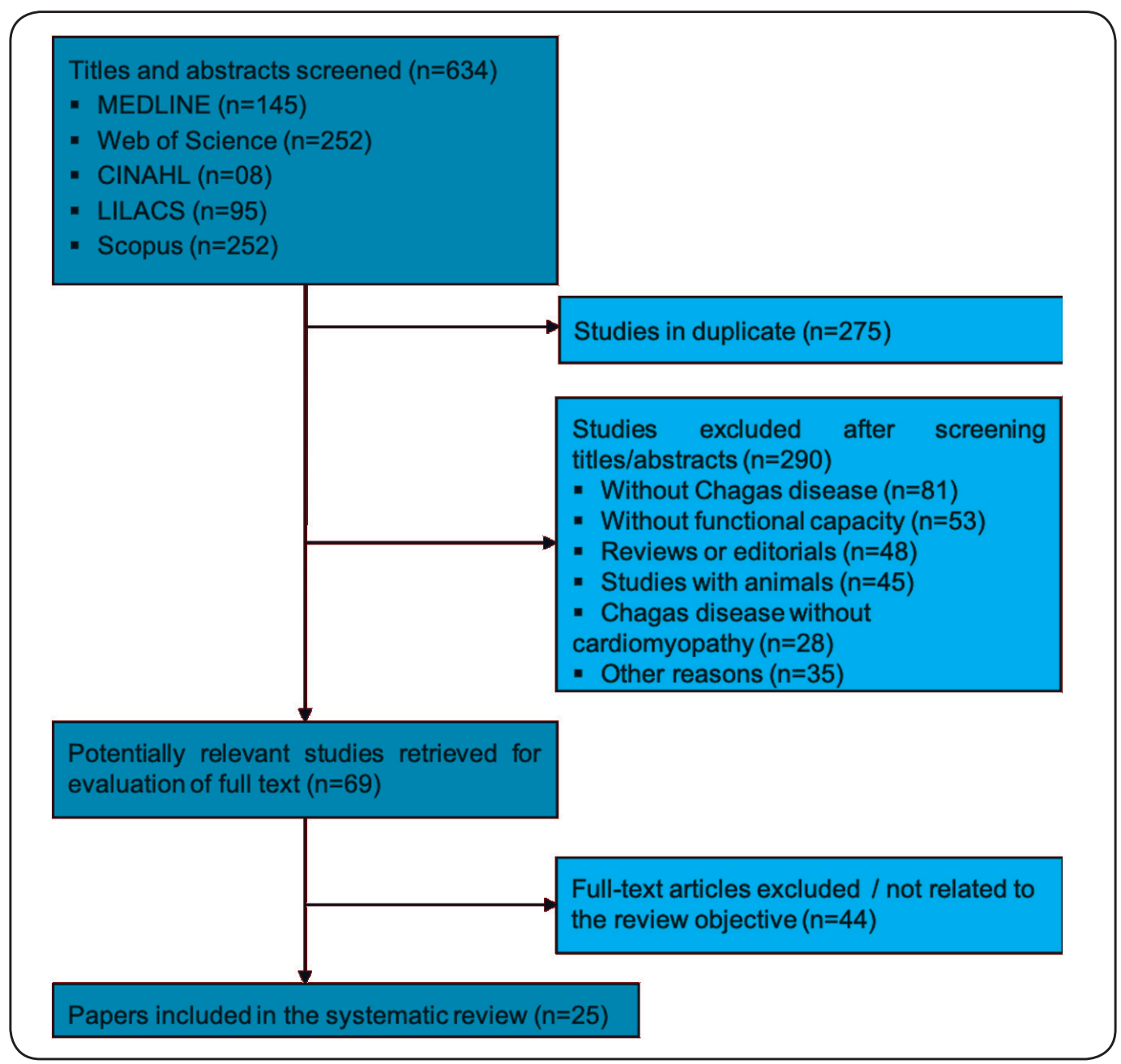

FIGURE 1: Flow of studies through the review. MEDLINE: Medical Literature Analysis and Retrieval System Online; CINAHL: Cumulative Index to Nursing and Allied Health Literature; LILACS: Latin American \& Caribbean Health Sciences Literature. 


\section{GENERAL ASPECTS OF FUNCTIONAL EVALUATION BY MAXIMAL EXERCISE TESTS}

Maximal exercise tests are widely used in the functional assessment of patients with ChC. The CPET is increasingly performed for patients with heart disease worldwide ${ }^{11}$ and is considered the gold standard for functional evaluation with significant prognostic value ${ }^{11-13}$. The major variables with functional and clinical significance obtained during the CPETs are peak oxygen uptake (VO2peak) and the slope of the increase of ventilation relative to carbon dioxide production ( $\mathrm{VE} / \mathrm{VCO} 2$ slope $)^{13}$.

The VO2peak, defined as the highest $\mathrm{VO}_{2}$ value reached during the exercise test, is used as a primary outcome in evaluating exercise capacity and the effectiveness of rehabilitation programs ${ }^{14,15}$. In addition to VO2peak, the VE/VCO2 slope is used to analyze ventilatory response during exercise and has been recommended as a parameter for the functional evaluation of patients with heart failure ${ }^{16}$. The $\mathrm{VE} / \mathrm{VCO} 2$ slope represents the efficiency of carbon dioxide elimination during physical exertion ${ }^{17}$. Another parameter, the anaerobic threshold (AT), reflects the functional capacity at submaximal intensity (many cardiac patients cannot reach maximum intensity) and does not depend on patient motivation ${ }^{18}$.

Unlike the CPET, in which VO2peak is directly measured by gas analysis, the conventional exercise test uses a formula to estimate the VO2peak. Despite the potential discrepancies between estimated and direct measurements of VO2peak, both methods aid in the prediction of cardiovascular risk and mortality ${ }^{19}$. Additionally, EIVA is a marker of cardiovascular mortality in patients with $\mathrm{ChC}^{20}$. As EIVA occurs frequently in $\mathrm{ChC}$ patients without apparent cardiac involvement ${ }^{8}$, the conventional maximal exercise test is clinically relevant for risk stratification in this population.

Nine articles on $\mathrm{ChC}$ reported the general aspects of functional evaluation by maximum tests and their determinants (Table 1). One study ${ }^{21}$ demonstrated no difference in VO2peak between groups with dilated $\mathrm{ChC}$ and with preserved LVEF. However, the study evaluated VO2peak using the conventional maximum exercise test, which could misreport the result. To clarify the hypothesis, two other studies compared functional capacities between the two clinical presentations of $\mathrm{ChC}$ using the CPET. Both found significant functional differences between groups. Mady et al. ${ }^{22}$ reported significantly lower VO2peak, $\mathrm{O} 2$ pulse, heart rate, minute ventilation (VE), and volume of exhaled carbon dioxide (VCO2) in patients with dilated $\mathrm{ChC}$ than in patients with preserved LVEF. Similarly, using CPET, Costa et al. ${ }^{23}$ demonstrated that lower VO2peak values and higher VE/VCO2 slope values were observed in patients with dilated $\mathrm{ChC}$ than in those with preserved LVEF. Previous findings suggest that the use of more accurate assessment methods will allow the detection of important functional changes in patients with dilated $\mathrm{ChC}$ compared to those in patients with preserved LVEF.

Correlation analyses between VO2peak and other variables of clinical importance in $\mathrm{ChC}$ were also identified. Only one ${ }^{24}$ of the included studies used CEPT to evaluate VO2peak, which was negatively correlated with the ratio of the early diastolic transmitral flow velocity to early diastolic mitral annular velocity (E/e' ratio) and was positively correlated with LVEF. When the sample was stratified according to dilated $\mathrm{ChC}$ and with preserved LVEF, the correlation between the $\mathrm{VO}$ 2peak and LVEF and E/e' ratio remained only in the dilated group.

The VO2peak in the conventional maximal exercise test was negatively correlated with age ${ }^{25,26}$, body mass index ${ }^{26}$, female $\operatorname{sex}^{26}$, the New York Heart Association (NYHA) class $^{26}$, and echocardiographic parameters (left ventricular end-diastolic diameter indexed by body surface area, deceleration time, E/e' ratio, right ventricle Tei index, and pulmonary artery systolic pressure $)^{25,27}$. Furthermore, the VO2peak was positively correlated with echocardiographic features, including $\mathrm{e}^{25,27}$, right ventricle $\mathrm{e}^{, 27}$, right ventricle $\mathrm{e}^{\prime} / \mathrm{A}^{\prime}$ ratio $^{27}$, and right ventricle systolic velocity ${ }^{27}$.

Despite its clinical importance, the general aspects of the VE/ VCO2 slope in patients with $\mathrm{ChC}$ remain undetermined. One study ${ }^{28}$ demonstrated a correlation between $\mathrm{VE} / \mathrm{VCO} 2$ slope and inspiratory muscle strength and observed a 1.2-fold increased risk of inspiratory muscle weakness in patients with impaired VE/VCO2. As it is an important variable in the functional and prognostic evaluation of patients with heart failure ${ }^{29-32}$, further studies are needed to verify the value of VE/VCO2 slope in patients with $\mathrm{ChC}$.

EIVA is one of the most important findings of the maximal exercise test as it can reflect electrocardiographic patterns during exertion. Pedrosa and $\mathrm{Campos}^{33}$ observed no differences in the prevalence of ventricular extrasystoles, pairs of extrasystoles, and non-sustained ventricular tachycardia and sustained monomorphic ventricular tachycardia detected by $24-\mathrm{h}$ Holter monitoring and those induced by exercise in ChC. Since the maximal exercise test showed results similar to those of 24-h Holter monitoring, which detects spontaneous arrhythmias, the test can be considered safe for patients.

\section{DETERMINANTS OF FUNCTIONAL CAPACITY}

Studies have verified the determinants of functional capacity in patients with $\mathrm{ChC}$. One such study ${ }^{26}$ in patients with dilated $\mathrm{ChC}$ and preserved LVEF reported that male sex, NYHA class, six-minute walk test (6MWT) distance, age, and body mass index were independent determinants of VO2peak, while echocardiographic findings were not.

Three studies ${ }^{24,25,27}$ assessed whether parameters evaluated on echocardiography were independent determinants of VO2peak. One of these studies ${ }^{24}$ reported the determinants of VO2peak evaluated by gas analysis in patients with $\mathrm{ChC}$ after stratifying the sample according to left systolic function and ventricular dilatation. They found that $\mathrm{LVEF}$ and $\mathrm{E} / \mathrm{e}$ ' ratio combined were strong determinants of VO2peak only in patients with dilated ChC. However, the sample size was small, and thus, the results should be interpreted with caution. Another study ${ }^{25}$ of the determinants of VO2peak in patients with dilated $\mathrm{ChC}$ found that age, male sex, E/e' ratio, and left atrial volume were independently associated with functional capacity. As in the aforementioned study ${ }^{24}$, the E/e' ratio remained a determinant of functional capacity in patients with dilated $\mathrm{ChC}$. However, LVEF was not associated with functional capacity in this population. Only weak correlations were identified between the traditional markers of left ventricular systolic function and exercise parameters. Although functional impairment and left ventricular systolic dysfunction are present in the advanced stages of cardiomyopathy, the reasons for the lack or weak association between LVEF and VO2peak is unclear. A reduction in functional 
TABLE 1: General aspects of the included studies $(n=9)$ that used the maximum exercise test for the functional evaluation of patients with ChC.

\begin{tabular}{|c|c|c|c|}
\hline STUDY & POPULATION & $\begin{array}{l}\text { EXERCISE } \\
\text { TEST }\end{array}$ & RESULTS \\
\hline $\begin{array}{l}\text { Mady et al. } \\
(1986)^{22}\end{array}$ & $\begin{array}{l}13 \text { patients with } \mathrm{ChC} \text { and preserved LVEF } \\
(30 \pm 5.76 \text { years) and } 15 \text { patients with dilated } \\
\text { ChC ( } 30 \pm 6.82 \text { years, NYHA II-III) }\end{array}$ & $\begin{array}{l}\text { CPET (Naughton } \\
\text { protocol, } \\
\text { treadmill) }\end{array}$ & $\begin{array}{l}\text { The VO2peak, O2 pulse, HR, VE, and VCO2 in patients } \\
\text { with dilated ChC were significantly lower compared to } \\
\text { those in patients with } \mathrm{ChC} \text { and preserved LVEF }(\mathrm{p}<0.05) \text {. }\end{array}$ \\
\hline $\begin{array}{l}\text { Pedrosa; } \\
\text { Campos } \\
(2004)^{33}\end{array}$ & $\begin{array}{l}20 \text { patients with } \mathrm{ChC} \text { and preserved } \\
\text { LVEF }(30 \% \text { male, } 51.2 \pm 11 \text { years, LVEF: } \\
59.3 \pm 14 \%) \text { and } 20 \text { patients with dilated } \\
\text { ChC }(20 \% \text { male, } 55.8 \pm 10 \text { years, LVEF: } \\
37.6 \pm 9.3 \%)\end{array}$ & $\begin{array}{l}\text { CPET (Bruce } \\
\text { protocol, } \\
\text { treadmill) }\end{array}$ & $\begin{array}{l}\text { No differences }(p>0.05) \text { were observed in the prevalence of } \\
\text { ventricular extrasystoles, pairs of extrasystoles, nonsustained } \\
\text { ventricular tachycardia, and sustained monomorphic ventricular } \\
\text { tachycardia, detected by 24-h Holter monitoring and those } \\
\text { induced by exercise both in dilated ChC and with preserved LVEF. }\end{array}$ \\
\hline
\end{tabular}

\begin{tabular}{|c|c|}
\hline $\begin{array}{l}\text { Rocha et al. } \\
(2005)^{21}\end{array}$ & $\begin{array}{l}154 \text { patients with ChC and preserved } \\
\text { LVEF [57\% male, } 41.7 \pm 9.3 \text { years, LVEF: } \\
62(58-65) \%] \text { and } 17 \text { patients with dilated } \\
\text { ChC [59\% male, } 42.8 \pm 9.2 \text { years, LVEF: } 35 \\
(31-39) \%]\end{array}$ \\
\hline
\end{tabular}

\section{Maximal}

Exercise Testing No differences were observed between groups with preserved LVEF and (Bruce protocol, treadmill) dilated $\mathrm{ChC}$ in VO2peak, maximum $\mathrm{HR}$, delta $\mathrm{HR}$, and effort time $(\mathrm{p}>0.05)$.
Lima et al. $\quad 40$ patients with dilated ChC; $49 \pm 8$ years; $(2010)^{25} \quad 58 \%$ male; NYHA I-II; LVEF: $36.3 \pm 7.8 \%$

\section{Maximal}

Exercise Testing

(Bruce protocol, treadmill)
The VO2peak was correlated with $E / E$ ' ratio $(r=-0.516 ; p=0.001)$ but not with LVEF, LVDd, and BNP. The predictors of VO2peak in the final multivariate modelwereage, femalesex, E/E'ratio, and leftatrialvolume $(\mathrm{LAV})\left(\mathrm{r}^{2}=0.521\right)$.
Nunes et al. $(2010)^{27}$
65 patients with $\mathrm{ChC}$ (comprising dilated ChC and with preserved LVEF); 48.6 \pm 9.1 years; $60 \%$ male; NYHA I-II); LVEF: $43.1 \pm 11.4 \%$
Maximal Exercise Test (treadmill, Bruce protocol)

The VO2peak was correlated with LVDd/BSA ( $r=-0.38 ; p=0.002)$, $e^{\prime}(r=0.40 ; p=0.001)$, E/e' ratio $(r=-0.37 ; p=0.003), R V e^{\prime}(r=0.29$; $p=0.025), R V e^{\prime} / A^{\prime}$ ratio $(r=0.41 ; p=0.001)$, RV systolic velocity $(r=$ $0.45 ; p<0.001)$, RV Tei index $(r=-0.28 ; p=0.029)$, and PASP $(r=$ $-0.36 ; p=0.009$ ). The VO2peak did not correlate with LVEF, E/A ratio, DT, LA volume index, E/ $\mathrm{Vp}$. The independent predictors of VO2peak were age, female sex and RV systolic velocity $\left(r^{2}=0.71\right)$.

In the overall study population, a significant correlation was observed between VO2peak and LVEF $(r=0.536, p=0.001)$ and E/e' ratio $(r=-0.399$; $p=0.022)$. In patients with dilated ChC $(n=16)$, the VO2peak was also correlated with $\operatorname{LVEF}(r=0.611, p=0.016)$ and with the ratio $E / e^{\prime}(r=-0.601$, $p=0.018)$. In the multivariate analysis, LVEF and E/e' ratio were strong predictors of VO2peak $\left(\mathrm{r}^{2}=0.723\right)$ only in patients with dilated $\mathrm{ChC}$.

Alvarenga et 35 patients with $\mathrm{ChC}$ (dilated and with preserved LVEF); $47.11 \pm 8.15$ years, $65 \%$ male; NYHA I-III; LVEF: 59.0 [41.0-64.0]
CPET (ramp

protocol treadmill)

\begin{tabular}{lll}
\hline & 41 patients with ChC (dilated and with & CPET (ramp \\
Costa et al. & preserved LVEF); $47.8 \pm 8.3$ years; $68 \%$ & protocol, \\
$(2014)^{23}$ & male; NYHA I-III & treadmill)
\end{tabular}

Patients with dilated ChC had lower VO2peak $(p=0.001)$ and 6MWT distance $(p=0.045)$ values and higher VE/VCO2 slope $(p=0.029)$ value compared to those in patients with $\mathrm{ChC}$ and preserved LVEF.

The VO2peak was correlated with age $(r=-0.490 ; p<0.001)$,

Costa et al. $\quad 81$ patients with ChC (dilated and with $(2017)^{26} \quad$ preserved LVEF); $48.6 \pm 8.1$ years; $63 \%$ male; NYHA I-III); LVEF: $43.7 \pm 13.7 \%$

\section{Maximal Exercise Test (treadmill)} sex ( $r=0.283 ; p=0.010)$, body mass index $(r=-0.333 ; p=0.002)$, NYHA functional class $(r=-0.667 ; p<0.001)$, and 6MWT distance $(r=0.527 ; p<0.001)$. The VO2peak was predicted by sex, NYHA functional class, 6MWT distance, age, and body mass index

VE/VCO2 slope was correlated with the percentage of maximal inspiratory pressure $(r=-0.446 ; p=0.004)$. The VO2peak was not correlated with maximal inspiratory pressure. In the final multivariate model, patients with impaired VE/VCO2 slope had a 1.2-fold increased risk for inspiratory muscle weakness (prevalence ratio $1.2,95 \% \mathrm{Cl} 1.1$ to $1.5, \mathrm{p}=0.001$ ).

Costa et al. $(2017)^{28}$
48 patients with $\mathrm{ChC}$ (dilated and with preserved LVEF); 56.4 (53.3-59.5) years; 29\% male; NYHA I-III; LVEF: 54.3 (48.6$59.9) \%$
CPET (ramp protocol, treadmill)

Data presented as mean \pm standard deviation; median (25-75\%); mean [95\% CI] or percentage. ChC: Chagas cardiomyopathy; NYHA: New York Heart Association; CPET: cardiopulmonary exercise testing; LVEF: left ventricular ejection fraction; VO2peak: peak oxygen uptake; HR: heart rate; VE: minuteventilation; LVDD: left ventricular end-diastolic diameter; BSA: body surface area; E: early diastolic transmitral flow velocity; e': early diastolic mitral annular velocity; E/A: ratio of early to late transmitral flow velocity; E/e' ratio: ratio of the early diastolic transmitral flow velocity to early diastolic mitral annular velocity; E/Vp: ratio of the early diastolic transmitral flow velocity to color M-mode flow propagation velocity; PASP: pulmonary artery systolic pressure; RV: right ventricular; DT: deceleration time; LA: left atrium; VE/VCO2 slope: minute ventilation/carbon dioxide production slope; 6MWT: Six-minute walk test.

capacity may precede the left ventricular systolic dysfunction? ${ }^{7}$. Therefore, electrical conduction disorders in the early stages of heart disease lead to significant myocardial damage ${ }^{34}$ that reduces cardiac output, limiting the duration of ventricular filling, increasing myocardial oxygen demand, and potentially contributing to exercise intolerance. In contrast, left ventricular systolic dysfunction is detected over years due to the inflammatory process, myocarditis, reparative fibrosis, and extracellular matrix alterations $s^{35}$.
A previous study ${ }^{36}$ emphasized the role of left ventricular diastolic function such as E/e' ratio as an important determinant of exercise intolerance in cardiac patients. The effect of left ventricular diastolic dysfunction on cardiac output may explain its association with functional capacity. During exertion, abnormalities in diastolic relaxation and left ventricular filling may result in filling rates below the required cardiac output even if the ventricular systolic properties are normal ${ }^{37}$. Inadequate cardiac output due to left ventricular 
filling can negatively affect exercise tolerance. Corroborating this hypothesis, Nunes et al. ${ }^{27}$ demonstrated that left ventricular diastolic function was not an independent determinant of functional capacity in patients with $\mathrm{ChC}$ without elevated left ventricular filling pressures (median $\mathrm{E} / \mathrm{e}^{\prime}$ ratio $=8$ ).

One study ${ }^{27}$ including more variables assessed on echocardiography and a larger sample than those in other studies found that age, sex, and right ventricle systolic velocity were associated with VO2peak. Together, these variables explained $71 \%$ of the variance in VO2peak. This study was the first to demonstrate the close relationship between the right ventricle and functional capacity being stronger than the systolic and diastolic functions of the left ventricle. The association between right ventricular systolic function and functional capacity were related to the elevation of pulmonary wedge pressure during exercise ${ }^{27}$, which leads to increased pulmonary resistance and consequently reduced right ventricular ejection and cardiac output during exercise ${ }^{27,38}$.

\section{THE PROGNOSTIC VALUE OF MAXIMAL EXERCISE TESTS}

Eight of the included articles verified the prognostic significance of maximal exercise tests (Table 2). Due to the fatigue and dyspnea experienced by $\mathrm{ChC}$ patients, especially those with

TABLE 2: Prognostic value of Maximal Exercise Tests in patients with $\mathrm{ChC}$ in the included studies $(n=8)$.

\begin{tabular}{|c|c|c|c|}
\hline STUDY & POPULATION & EXERCISE TEST & RESULTS \\
\hline $\begin{array}{l}\text { De Paola et al. } \\
(1995)^{43}\end{array}$ & $\begin{array}{l}69 \text { patients with ChC (dilated and } \\
\text { preserved LVEF), } 46 \pm 12 \text { years; } \\
54 \% \text { male; NYHA I-III, LVEF } \\
46.6 \pm 18.6 \% \text {. Follow-up period: } \\
24 \pm 15 \text { months. Endpoint: sudden } \\
\text { death }\end{array}$ & $\begin{array}{l}\text { Maximal Exercise } \\
\text { Test (Bruce } \\
\text { protocol, treadmill) }\end{array}$ & $\begin{array}{l}\text { The number of patients with ventricular tachycardia at baseline was significantly } \\
\text { higher in the sudden cardiac death group when compared to survivors }(p<0.05) \text {. }\end{array}$ \\
\hline $\begin{array}{l}\text { Silva et al. } \\
(2017)^{41}\end{array}$ & $\begin{array}{l}45 \text { patients with dilated } \mathrm{ChC} \text {, } \\
50.24 \pm 10.79 \text { years; } 100 \% \text { male. } \\
\text { Endpoint: death }\end{array}$ & $\begin{array}{l}\text { CPET (cycle } \\
\text { ergometer) }\end{array}$ & $\begin{array}{l}\text { The VO2peak AT is an independent predictor of death (AUC=0.706). When } \\
\text { both Rassi score and AT were defined as independent variables. VO2peak AT } \\
\text { increases the accuracy of the Rassi score for mortality prediction by } 5 \% \text {. }\end{array}$ \\
\hline $\begin{array}{l}\text { Souza et al. } \\
(2015)^{42}\end{array}$ & $\begin{array}{l}21 \text { patients with dilated ChC, } \\
54.5 \pm 11.9 \text { years, } 38.1 \% \text { male, } \\
\text { NYHA III-IV, LVEF } 29.2 \pm 6.0 \% \text {. } \\
\text { Follow-up period: } 24 \text { months. } \\
\text { Endpoint: cardiac death }\end{array}$ & $\begin{array}{l}\text { CPET (ramp } \\
\text { protocol, treadmill) }\end{array}$ & $\begin{array}{l}\text { Differences between non-survivors ChC compared to survivors included lower } \\
\text { peak HR ( } p=0.026) \text {, peak SBP }(p=0.038) \text {, VO2peak }(p=0.043), \text { VO2peak AT } \\
(p=0.016) \text {, circulatory power }(p=0.006) \text { and ventilatory power }(p=0.008) \text {. In the } \\
\text { logistic regression, only circulatory power was independently associated with } \\
\text { survival (OR } 17.3[95 \% \text { Cl: } 1.39 \text { to } 217.0]) \text {. The circulatory power showed good } \\
\text { accuracy in identify mortality (cut-off point } \leq 1280) \text {. }\end{array}$ \\
\hline $\begin{array}{l}\text { Ritt et al. } \\
(2013)^{13}\end{array}$ & $\begin{array}{l}55 \text { patients with dilated ChC, } \\
52 \pm 9 \text { years, } 69 \% \text { male, NYHA } \\
\text { II-IV, LVEF } 27.6 \pm 6.6 \% \text {. Follow-up } \\
\text { period: } 32 \pm 19 \text { months. Endpoint: } \\
\text { cardiac death }\end{array}$ & $\begin{array}{l}\text { CPET (ramp } \\
\text { protocol, treadmill) }\end{array}$ & $\begin{array}{l}\text { The VO2peak }(p=0.03) \text { and VE/VCO2 slope }(p=0.01) \text { differed significantly } \\
\text { between survivors and non-survivors. The VO2peak was correlated with } \\
\text { MLwHRQ }(r=-0.301 ; p=0.02 \text { ) and showed good accuracy in identifying mortality } \\
\text { (cut-off } \leq 18 \mathrm{~mL} / \mathrm{kg} / \mathrm{min}) \text {. The VE/VCO2 slope showed good accuracy in } \\
\text { identifying mortality (cut-off } \geq 32.5 \text {. After adjusting for age, LVEF, and Chagas } \\
\text { score, VE/VCO2 slope remained an independent predictor of mortality (adjusted } \\
\text { HR: } 2.80,95 \% \mathrm{Cl}: 1.30 \text { to } 5.80 \text {, and } p=0.001 \text { for those with VE/VCO2 slope } \\
\geq 32.5 \text { ). }\end{array}$ \\
\hline
\end{tabular}

\begin{tabular}{|c|c|c|c|}
\hline $\begin{array}{l}\text { Pedrosa et al. } \\
(2011)^{44}\end{array}$ & $\begin{array}{l}130 \text { patients with ChC (dilated } \\
\text { and with preserved LVEF), } \\
50.7 \pm 10.3 \text { years, } 40.8 \% \text { male. } \\
\text { Follow-up period: } 9.9 \text { years } \\
\text { (range, } 132 \text { days to } 17 \text { years). } \\
\text { Endpoint: cardiovascular death }\end{array}$ & $\begin{array}{l}\text { CPET (Bruce } \\
\text { protocol) }\end{array}$ & $\begin{array}{l}\text { The prevalence of EIVA was } 43.1 \% \text {. Sex, age, and cardiothoracic index were } \\
\text { not associated with EIVA. LVEF showed a statistically significant association } \\
\text { with EIVA }(p=0.01) \text {. The presence of EIVA alone was not a predictor of mortality } \\
\text { but predicted mortality in Cox analysis, only when associated with age and } \\
\text { cardiothoracic index } \geq 0.5 \text { (hazard ratio }=4.3 \text { [ } 95 \% \mathrm{Cl}: 1.6 \text { to } 11.4] \text {; } p=0.004 \text { ). }\end{array}$ \\
\hline $\begin{array}{l}\text { Costa et al. } \\
(2018)^{40}\end{array}$ & $\begin{array}{l}49 \text { patients with dilated ChC, } \\
50 \pm 7 \text { years; } 57 \% \text { male; NYHA } \\
\text { I-III, LVEF: } 36.0 \text { [31.0-41.0]\%. } \\
\text { Follow-up period: } 39 \pm 14 \text { months. } \\
\text { Endpoint: cardiac death }\end{array}$ & $\begin{array}{l}\text { Maximal Exercise } \\
\text { Testing (Bruce } \\
\text { protocol, treadmill) }\end{array}$ & $\begin{array}{l}\text { Survivors had higher VO2peak }(\mathrm{p}=0.048) \text { than non-survivors. In the final } \\
\text { model, VO2peak (hazard ratio } 1.2,95 \% \mathrm{Cl}: 1.0 \text { to } 1.3 ; \mathrm{p}=0.009 \text { ) remained an } \\
\text { independent predictor of cardiac death in } \mathrm{ChC} \text {. The optimal cut-off point for } \\
\text { VO2peak in predicting death was } 25 \mathrm{~mL} / \mathrm{kg} / \mathrm{min} \text {. However, the established cutoff } \\
\text { point failed to demonstrate a difference between the groups with VO2peak } \\
\text { below and above } 25 \mathrm{~mL} / \mathrm{kg} / \mathrm{min} \text {. }\end{array}$ \\
\hline $\begin{array}{l}\text { Mady et al. } \\
(1994)^{12}\end{array}$ & $\begin{array}{l}104 \text { patients with dilated ChC, } \\
40.3 \pm 9.0 \text { years; } 100 \% \text { male; } \\
\text { NYHA II-IV, LVEF: } 37.4 \pm 11.1 \% \text {. } \\
\text { Follow-up period: } 41 \pm 12 \text { months. } \\
\text { Endpoint: cardiac death }\end{array}$ & $\begin{array}{l}\text { CPET (Naughton } \\
\text { protocol, treadmill) }\end{array}$ & $\begin{array}{l}\text { The survivor group showed higher LVEF }(=0.001) \text {, higher VO2peak }(p=0.001) \text {, } \\
\text { and better NYHA functional class }(p=0.001) \text { than that of those in the non-survivor } \\
\text { group. In the multivariate model, VO2peak }(p=0.001) \text { and LVEF }(p=0.008) \\
\text { remained independent predictors of cardiac death. Survival was significantly } \\
\text { better in patients with VO2peak }>20 \mathrm{~mL} / \mathrm{kg} / \mathrm{min} \text {. }\end{array}$ \\
\hline $\begin{array}{l}\text { Costa et al. } \\
(2019)^{39}\end{array}$ & $\begin{array}{l}75 \text { patients with ChC (dilated } \\
\text { and with preserved LVEF), } \\
48.4 \pm 8.0 \text { years; } 61 \% \text { male; } \\
\text { NYHA I-III, LVEF: } 41.0 \text { [35.0- } \\
53.5] \% \text {. Follow-up period: } 41 \pm 12 \\
\text { months. Endpoint: death, heart } \\
\text { transplantation, or ischemic event }\end{array}$ & $\begin{array}{l}\text { Maximal Exercise } \\
\text { Test (Bruce } \\
\text { protocol, treadmill) }\end{array}$ & $\begin{array}{l}\text { Patients with adverse events had lower LVEF }(p=0.002) \text {, higher LVDD ( } p=0.019) \\
\text { and worse mental component of HRQL }(p=0.043) \text { compared to those in } \\
\text { patients without adverse events. No differences were observed in age, sex, } \\
\text { NYHA functional class, VO2peak, \%HR achieved during exercise test, and } \\
\text { HR recovery after exercise testing between groups. In the univariate analysis, } \\
\text { VO2peak, \%HR achieved during exercise test, and HR recovery after exercise } \\
\text { testing were not associated with adverse events. }\end{array}$ \\
\hline
\end{tabular}

Data presented as mean \pm standard deviation; mean $[95 \% \mathrm{Cl}]$ or percentage. Abbreviations: ChC: Chagas cardiomyopathy; NYHA: New York Heart Association; LVEF: left ventricular ejection fraction; CPET: Cardiopulmonary Exercise Testing; VO2peak: peak oxygen uptake; EIVA: exercise-induced ventricular arrhythmias; AT: anaerobic threshold; AUC: area under the ROC curve; ROC: receiver operating curve; MLwHFQ: Minnesota Living with Heart Failure Questionnaire; HRQoL: health-related quality of life; LVDD: left ventricular end-diastolic diameter; E/e' ratio: ratio of the early diastolic transmitral flow velocity to early diastolic mitral annular velocity; VE/VCO2 slope: minute ventilation/carbon dioxide production slope; 6MWT: six-minute walk test. 
severely impaired systolic function and cardiac chamber dilation, the importance of functional assessment of these patients by exercise tests is undeniable. However, unlike heart failure due to other etiologies, little information is available regarding the prognostic value of the parameters evaluated during exertion in patients with $\mathrm{ChC}$.

The prognostic values of VO2peak and VE/VCO2 slope in patients with heart failure are well-established ${ }^{29-32}$. Thus, they are also expected to have significance in predicting poor outcome in patients with ChC. Four studies evaluated the role of VO2peak in the prediction of adverse events. Costa et al. ${ }^{39}$ was the only study to include $\mathrm{ChC}$ patients with both dilated $\mathrm{ChC}$ and with preserved LVEF, showing that VO2peak was not associated with poor prognosis. However, the authors selected patients with a different clinical and functional profile and adopted different outcome criteria in addition to cardiac death. Patients demonstrate clinical heterogeneity even within the same disease stage. For prognostic purposes, stratifying patients into more homogeneous criteria could allow more reliable and robust analyses.

Ritt et al. ${ }^{13}$ verified that in patients with only dilated $\mathrm{ChC}$, VO2peak showed good accuracy in identifying mortality. Patients with VO2peak $\leq 18 \mathrm{~mL} / \mathrm{kg} / \mathrm{min}$ had a mean survival of $29 \pm 3$ months versus $46 \pm 5$ months for those with VO2peak $>18 \mathrm{~mL} / \mathrm{kg} /$ min. However, after adjusting for age, LVEF, and Chagas score, VO2peak was no longer significantly associated with mortality.

In patients with dilated $\mathrm{ChC}$, Mady et al. ${ }^{12}$ demonstrated that only VO2peak and LVEF were independent predictors of death. The survival rate was significantly higher in patients with VO2peak $>20$ $\mathrm{mL} / \mathrm{kg} / \mathrm{min}$. All patients with VO2peak values below $10 \mathrm{~mL} / \mathrm{kg} / \mathrm{min}$ died before 1 year. Similarly, another study ${ }^{40}$ that also evaluated the prognostic value of VO2peak in dilated $\mathrm{ChC}$ found that VO2peak was an independent predictor of death in patients with $\mathrm{ChC}$ (optimal cut-off: $25 \mathrm{~mL} / \mathrm{kg} / \mathrm{min}$ ). However, the established cutoff point failed to differentiate between groups with $\mathrm{VO} 2$ peak values below and above $25 \mathrm{~mL} / \mathrm{kg} / \mathrm{min}$. We believe that VO2peak in dilated $\mathrm{ChC}$ is at least associated with a worse prognosis. However, due to the limited number of studies and the small sample sizes used, more studies are needed to confirm this hypothesis.

Only one study ${ }^{13}$ assessed the prognostic significance of the VE/ $\mathrm{VCO} 2$ slope and reported good accuracy in identifying mortality risk. Patients with a VE/VCO2 slope $\geq 32.5$ had a mean survival of $28 \pm 3$ months versus $47 \pm 5$ months for those with a slope of $<32.5$. After adjusting for age, LVEF, and Chagas score, VE/VCO2 slope remained an independent predictor of mortality. Therefore, this variable may be a valuable marker of worse outcomes in dilated $\mathrm{ChC}$.

The prognostic values of two other variables assessed using CEPT were also verified. VO2peak AT was identified as an independent predictor of death in patients with dilated $\mathrm{ChC}^{41}$ and circulatory power showed good accuracy in identifying the risk of mortality ${ }^{42}$.

EIVA may also be a finding of prognostic importance in this population as ventricular arrhythmias during exertion may be detectable even in asymptomatic patients. One study ${ }^{43}$ reported a significantly higher number of patients with ventricular tachycardia during exercise test at baseline in the sudden cardiac death group than that in the survivor group. Another study ${ }^{44}$ evaluating the prognostic value of EIVA in patients with $\mathrm{ChC}$ (dilated and with preserved LVEF) demonstrated that the presence of EIVA alone was not a predictor of mortality. However, the presence of EIVA can predict mortality when associated with age and cardiothoracic index $\geq 0.5$.

\section{THE ROLE OF FIELD TESTS IN FUNCTIONAL EVALUATION}

Although the CPET is the gold standard for measuring exercise capacity, field tests have emerged as valuable tools for patients unable to perform maximal exercise tests or in places where the CPET is not available. Among field tests, the 6MWT and Incremental Shuttle Walk Test (ISWT) are most often used for patients with heart and pulmonary diseases ${ }^{45}$.

The 6MWT is an easy-to-perform test and is well-tolerated by patients. Patients are instructed to walk as far as possible in six minutes along a corridor (30 meters), without running ${ }^{46}$. The outcome is the final distance. However, in the 6MWT, patients tend to select a comfortable speed and not stress themselves with a maximal effort ${ }^{47}$.

Compared to the 6MWT, the ISWT employs a standardized methodology and a progressive character that is more similar to the maximum tests. Patients are required to walk at a defined speed in a 10-meter corridor, as dictated by a series of beeps from an audio recorder $^{48}$. The walking speed is progressively increased at 1-min intervals for a total of 12 stages. The test ends when the patient fails to complete a shuttle in the time required. The target outcome is the final distance.

Field tests are widely used in patients with $\mathrm{ChC}$ and can provide valuable information about the functional status of the patient. The present review included 10 articles that applied field tests in ChC. In the 6MWT, the distance walked was positively correlated with VO2peak ${ }^{23,26,49}$, LVEF $^{50}$, hemoglobin levels ${ }^{51}$, inspiratory muscle strength $^{52}$, and some Short-form Health Survey (SF-36) domains ${ }^{53}$. Furthermore, the 6MWT was correlated with VO2peak in both dilated $\mathrm{ChC}$ and with preserved $\mathrm{LVEF}^{23}$, although the correlation was stronger in the dilated group.

Moreover, the 6MWT distance was inversely correlated with levels of blood biomarkers, including brain natriuretic peptide (BNP) levels ${ }^{50,53}$ and monocyte chemoattractant protein-1 $(\mathrm{MCP}-1)^{50}$ as well as some echocardiographic features ${ }^{53}$. The distance was strongly correlated with health-related quality of life evaluated by the Minnesota Living with Heart Failure Questionnaire (MLwHRQ) $)^{13,51,53}$. The 6MWT distance was the only independent determinant of MLwHRQ score. The presence of systemic arterial hypertension did not reduce the functional capacity of patients with $\mathrm{ChC}^{51}$.

Costa et $\mathrm{al}^{26}$ developed and validated an equation based on sex, NYHA class, 6MWT distance, age, and body mass index to predict the VO2peak evaluated by gas analysis in patients with $\mathrm{ChC}\left(\mathrm{R}^{2}=0.61\right)$.

Several studies evaluated the prognostic value of the 6MWT. ${ }^{13,54}$ Ritt et al. ${ }^{13}$ reported differences in the distances between survivors and non-survivors. However, the test did not provide accurate 
information on the mortality of patients with dilated ChC. Similarly, Costa et al. ${ }^{54}$ also found no prognostic value of the 6MWT distance in 60 patients with dilated $\mathrm{ChC}$.

The ISWT is another test widely used for functional assessment of patients with heart diseases. In $\mathrm{ChC}$ and samples comprising dilated and preserved LVEF, the ISWT distance was positively correlated with VO2peak ${ }^{49,55,56}$ and some SF-36 domains ${ }^{56}$. Significant negative correlations were reported between ISWT distance and VE/VCO2 slope $^{49}$ and MLwHRQ score ${ }^{56}$.
Prediction equations have been proposed to estimate the VO2peak assessed using CPET with ISWT ${ }^{55}$. The equations are based on the ISWT distance, NYHA class, and sex (Table 3 ). Unfortunately, no study has verified the prognostic significance of the test in predicting adverse events in patients with $\mathrm{ChC}$.

Finally, one study ${ }^{49}$ compared the distances walked between field tests (6MWT and ISWT) and the accuracy of both in the identification of patients with functional impairment (VO2peak $<20 \mathrm{~mL} / \mathrm{kg} / \mathrm{min})$. No significant differences were observed between

TABLE 3: Functional and prognostic evaluation in patients with $\mathrm{ChC}$ by field tests $(n=10)$

\begin{tabular}{|c|c|c|c|}
\hline STUDY & POPULATION & EXERCISE TESTS & RESULTS \\
\hline $\begin{array}{l}\text { Sousa et al. } \\
(2008)^{50}\end{array}$ & $\begin{array}{l}38 \text { patients with dilated } \mathrm{ChC}, 48 \pm 10 \\
\text { years; } 68 \% \text { male; NYHA I-III, } \\
\text { LVEF }<55 \%\end{array}$ & 6MWT & $\begin{array}{l}\text { The 6MWT distance was correlated with MCP-1 values }(r=-0.358, p=0.04) \text {, } \\
\text { BNP levels }(r=-0.349, p=0.04) \text {, and LVEF }(r=0.451, p=0.004) \text { but not with } \\
\text { NYHA functional class }(r=-0.130, p=0.435) \text {. }\end{array}$ \\
\hline $\begin{array}{l}\text { Dourado et al. } \\
(2010)^{51}\end{array}$ & $\begin{array}{l}60 \text { patients with ChC: } 55 \pm 14 \text { years; } \\
68 \% \text { male; } 25 \% \text { in NYHA III-IV; } \\
\text { LVEF: } 44.0 \pm 13.8 \% \text { and } 38 \text { patients } \\
\text { with ChC and systemic arterial } \\
\text { hypertension: } 63 \pm 10 \text { years; } 88 \% \\
\text { male; } 21 \% \text { in NYHA III-IV; LVEF: } \\
51.8 \pm 12.9 \%\end{array}$ & 6MWT & $\begin{array}{l}\text { No difference in } 6 \text { MWT distance between groups with and without systemic } \\
\text { arterial hypertension }(p>0.05) \text {. In the systemic arterial hypertension group, } \\
\text { the } 6 \text {, } W \text {, distance was correlated with MLwHFQ }(r=-0.51 ; p=0.001) \text {. In } \\
\text { the group without systemic arterial hypertension, the } 6 M W T \text { distance was } \\
\text { correlated with hemoglobin levels }(r=0.34 ; p=0.007) \text { and MLwHFQ }(r=-0.38 \text {; } \\
p=0.003) \text {. }\end{array}$ \\
\hline $\begin{array}{l}\text { Ritt et al. } \\
(2013)^{13}\end{array}$ & $\begin{array}{l}55 \text { patients with dilated ChC }(52 \pm 9 \\
\text { years, } 69 \% \text { male, NYHA II-IV, LVEF: } \\
27.6 \pm 6.6 \%) \text {. Follow-up period: } 32 \pm 19 \\
\text { months; endpoint: cardiac death }\end{array}$ & $\begin{array}{l}\text { CPET (ramp } \\
\text { protocol, treadmill) } \\
\text { and } 6 \mathrm{MWT}\end{array}$ & $\begin{array}{l}\text { The 6MWT was correlated with MLwHRQ }(r=-0.375 ; p=0.007) \text { and was } \\
\text { the only independent determinant of MLwHRQ (each } 10 \text {-min increase in } \\
\text { distance walked was associated with a } 0.7 \text {-point reduction in MLHFQ score); } \\
\text { no prognostic value. }\end{array}$ \\
\hline $\begin{array}{l}\text { Costa et al. } \\
(2014)^{56}\end{array}$ & $\begin{array}{l}35 \text { patients (dilated and preserved } \\
\text { LVEF), } 47.1 \pm 8.2 \text { years, } 66 \% \text { male, } \\
\text { NYHA I-III and LVEF: } 59(41-64) \%\end{array}$ & $\begin{array}{l}\text { CPET (ramp } \\
\text { protocol, treadmill) } \\
\text { and ISWT }\end{array}$ & $\begin{array}{l}\text { ISWT distance was correlated with VO2peak }(r=0.587 ; p<0.001) \text {, MLwHRQ } \\
\text { score }(r=-0.460 ; p=0.006) \text {, and SF-36 domains physical functioning }(r=0.435 \text {; } \\
p=0.009) \text {, role physical }(r=0.447 ; p=0.008) \text {, and mental health }(r=0.430 \text {; } \\
p=0.011) \text {. }\end{array}$ \\
\hline $\begin{array}{l}\text { Costa et al. } \\
(2014)^{23}\end{array}$ & $\begin{array}{l}41 \text { patients with ChC (dilated and } \\
\text { with preserved LVEF), } 47.8 \pm 8.3 \\
\text { years; } 68 \% \text { male; NYHA I-III }\end{array}$ & $\begin{array}{l}\text { CPET (ramp } \\
\text { protocol, treadmill) } \\
\text { and } 6 \mathrm{MWT}\end{array}$ & $\begin{array}{l}\text { Patients with dilated ChC showed lower 6MWT distance }(p=0.045) \\
\text { compared to that in patients with preserved LVEF. The 6MWT distance was } \\
\text { correlated with VO2peak }(r=0.586 ; p<0.001) \text { but not with VE/VCO2 slope } \\
(r=-0.046 ; p=0.776) \text {. The 6MWT distance was correlated with VO2peak } \\
\text { in both dilated ChC }(n=20, r=0.612 ; p=0.005) \text { and preserved LVEF }(n=21 \text {, } \\
r=0.463 ; p=0.035) \text { groups. }\end{array}$ \\
\hline $\begin{array}{l}\text { Alves et al. } \\
(2016)^{55}\end{array}$ & $\begin{array}{l}32 \text { patients with ChC ( } 6 \text { with dilated } \\
\text { ChC and } 26 \text { with preserved LVEF), } \\
58.8 \pm 9.0 \text { years; } 18.7 \% \text { male; NYHA } \\
\text { I-III, LVEF: } 62.4 \pm 13.4 \%\end{array}$ & $\begin{array}{l}\text { CPET (Bruce } \\
\text { protocol, treadmill) } \\
\text { and ISWT }\end{array}$ & $\begin{array}{l}\text { The ISWT distance was correlated with VO2peak }(r=0.456 ; p=0.009) \text {. In } \\
\text { women, the VO2peak was predicted by the formula } 13.97+0.02 \times \text { ISWT } \\
\left.\text { distance (for NYHA I) or } 11.36+0.02 \times \text { ISWT distance (for NYHA }{ }^{3} \mid I\right) \text {. In men, } \\
\text { the VO2peak was predicted by the formula } 12.21+0.03 \times \text { ISWT distance (for } \\
\text { NYHA I) or } 9.60+0.03 \times \text { ISWT distance (for NYHA } \text { I III). }^{3}\end{array}$ \\
\hline $\begin{array}{l}\text { Chambela et al. } \\
(2017)^{53}\end{array}$ & $\begin{array}{l}40 \text { patients with dilated ChC, } 60 \pm 12 \\
\text { years; } 47 \% \text { male; NYHA I-III, LVEF: } \\
35 \pm 12 \%\end{array}$ & 6MWT & $\begin{array}{l}\text { The 6MWT distance was correlated with BNP }(r=-0.37 ; p=0.02) \text { and } \\
\text { echocardiographic features, including E velocity }(r=-0.38 ; p=0.002) \text {, E/E } \\
\text { ratio }(r=-0.32 ; p=0.05) \text {, LV diastolic dysfunction }(r=-0.36 ; p=0.03) \text {, mitral } \\
\text { regurgitation }(r=-0.53 ; p<0.001) \text {, and PASP }(r=-0.42 ; p=0.02) \text {. The 6MWT } \\
\text { distance was also correlated with the SF- } 36 \text { domains physical functioning } \\
(r=0.46 ; p=0.008) \text {, physical role functioning }(r=0.37 ; p=0.04) \text {, and bodily pain } \\
(r=0.43 ; p=0.014) \text { as well as MLwHRQ }(r=-0.54 ; p=0.002) \text {. }\end{array}$ \\
\hline $\begin{array}{l}\text { Costa et al. } \\
(2017)^{26}\end{array}$ & $\begin{array}{l}81 \text { patients with ChC (dilated and } \\
\text { with preserved LVEF), } 48.6 \pm 8.1 \\
\text { years; } 63 \% \text { male; NYHA I-III, LVEF: } \\
43.7 \pm 13.7 \%\end{array}$ & $\begin{array}{l}\text { Maximal Exercise } \\
\text { Test (treadmill) and } \\
6 \mathrm{MWT}\end{array}$ & $\begin{array}{l}\text { The VO2peak was correlated with the } 6 \text { MWT distance }(r=0.527 ; p<0.001) \\
\text { and VO2peak was predicted by the formula } 53.43+(1.35 \times \text { sex })-(5.59 \times \\
\text { NYHA }+(0.01 \times 6 \text { MWT distance })-(0.29 \times \text { age })-(0.035 \times \text { BMI })\end{array}$ \\
\hline $\begin{array}{l}\text { Costa et al. } \\
(2017)^{54}\end{array}$ & $\begin{array}{l}60 \text { patients with dilated ChC, } \\
52.6 \pm 9.4 \text { years; } L V E F: 27.1 \pm 5.5 \% \text {. } \\
\text { Follow-up period: } 7.5 \text { years. } \\
\text { Endpoint: death }\end{array}$ & 6MWT & $\begin{array}{l}\text { The 6MWT was not a predictor of death. The independent predictors of } \\
\text { death were non-sustained ventricular arrhythmias in } 24 \mathrm{~h} \text { Holter monitoring } \\
\text { and left atrium volume index ( } p<0.05 \text { for both). }\end{array}$ \\
\hline $\begin{array}{l}\text { Costa et al. } \\
(2018)^{49}\end{array}$ & $\begin{array}{l}35 \text { patients with ChC (dilated and } \\
\text { with preserved LVEF), } 47.1 \pm 8.2 \\
\text { years; } 66 \% \text { male; NYHA I-III, LVEF: } \\
59.0[41.0-64.0]\end{array}$ & $\begin{array}{l}\text { CPET (ramp } \\
\text { protocol, treadmill), } \\
6 \mathrm{MWT} \text { and ISWT }\end{array}$ & $\begin{array}{l}\text { The VO2peak was correlated with 6MWT distance }(r=0.577 ; p<0.001) \text { and } \\
\text { ISWT distance }(r=0.587 ; p<0.001) \text {. Only the ISWT was correlated with } \\
\text { the VE/VCO2 slope }(r=-0.339 ; p=0.003) \text {. The optimal distances to identify } \\
\text { patients with functional impairment were } 520 \mathrm{~m} \text { for the } 6 \text { MWT and } 400 \text { m } \\
\text { for the ISWT. }\end{array}$ \\
\hline
\end{tabular}

Data presented as mean \pm standard deviation; median (25-75\%); mean [95\% Cl] or percentage. Abbreviations: ChC: Chagas cardiomyopathy; NYHA: New York Heart Association; LVEF: left ventricular ejection fraction; 6MWT: six-minute walk Test; MLwHFQ: Minnesota Living with Heart Failure Questionnaire; CPET: Cardiopulmonary Exercise Testing; VO2peak: peak oxygen uptake; VE/VCO2 slope: minute ventilation/carbon dioxide production slope; HRQoL: health-related quality of life; SF-36: Short-form of Health Survey; ISWT: Incremental Shuttle Walk Test; BNP: brain natriuretic peptide; E velocity: peak early diastolic filling velocity; E/E' ratio: ratio of the early diastolic transmitral flow velocity to early diastolic mitral annular velocity; PASP: pulmonary artery systolic pressure; AUC: area under the ROC curve; MCP-1: monocyte chemoattractant protein-1. 
the distances walked. Furthermore, the optimal distances to identify patients with functional impairment were $520 \mathrm{~m}$ for the $6 \mathrm{MWT}$ and $400 \mathrm{~m}$ for the ISWT.

\section{CURRENT CHALLENGES}

Chagas disease persists as an important and neglected cause of loss of years of healthy life due to premature mortality and disability ${ }^{57}$; furthermore, robust clinical trials are scarce in Chagas disease and the recommendations are often based on guidelines for other cardiopathies ${ }^{58,59}$.

Moreover, few studies have verified the effectiveness of the variables assessed using the exercise tests in predicting patient survival. The VO2peak is an important criterion for heart transplantation in patients with $\mathrm{ChC}^{60}$; however, its prognostic role should be better understood in the context of preventive strategies, risk stratification, and early diagnosis. In addition, it is necessary to establish strong cut-off points or deepen the recognition of existing ones. The criteria proposed by Weber et al. ${ }^{16}$ are well-founded but directed at patients with non-ChC heart failure and it remains unknown if they are effective in $\mathrm{ChC}$. In patients with $\mathrm{ChC}$ and preserved LVEF, is the exercise test useful only for the assessment of EIVA, chronotropic incompetence, and ischemia, or can some functional variables contribute to signal an unfavorable prognosis in the medium or long term?

Chagas is a neglected tropical disease for which many studies are performed in endemic areas, usually with low human development indexes, limited resources, and few technological devices. Thus, studies on functional assessment using field tests should be encouraged. However, some questions remain unanswered. For instance, can field tests provide prognostic information? Are both 6MWT and ISWT safe for patients or can they trigger or exacerbate ventricular arrhythmias? Which of the field tests is more effective in identifying patients with poor outcomes? Do they predict survival in a wide spectrum of patients with $\mathrm{ChC}$ or just a subgroup according to systolic function? What is the responsiveness of the field tests?

Finally, with the population aging, elderly patients with infection deserve special attention because they are a vulnerable group owing to the combination of Chagas disease and chronic-degenerative comorbidities $^{61}$. Several studies have targeted this population. Elderly patients with Chagas disease usually present the cardiac form $^{61-63}$, and comorbidities are detected in approximately $60 \%$ of patients ${ }^{62}$. Furthermore, elderly patients with $\mathrm{ChC}$ have lower VO2peak values and a higher prevalence of ventricular arrhythmias than do younger patients with the same clinical presentation ${ }^{64}$. Therefore, studies addressing functional evaluation and exercise prescription in situations with the coexistence of $\mathrm{ChC}$ and comorbidities, including hypertension, osteoporosis, osteoarthritis, dyslipidemia, and diabetes, are required.

\section{FINAL CONSIDERATIONS}

In patients with $\mathrm{ChC}$, the VO2peak was correlated with many demographic, clinical, and echocardiographic variables. The main echocardiographic determinants included left ventricular diastolic function and right ventricular systolic velocity. In addition, VO2peak was associated with higher mortality. The VE/VCO2 slope emerged as a potential prognostic measure evaluated by the
CPET. Finally, both field tests (6MWT and ISWT) demonstrated efficacy in the functional evaluation of patients with ChC. However, the prognostic value of the tests remains unknown and further studies are needed, considering their low operational costs and the setting of Chagas disease.

\section{AUTHORS' CONTRIBUTION}

HSC, MRA, and KKPM: Performed database searches; MRA, MMOL, ANRL, and VAM: Analyzed data; HSC, PHSF, and VPL: Wrote the paper; MFFM, MCPN, and MOCR: Critical manuscript review.

\section{CONFLICT OF INTEREST}

The authors declare that there is no conflict of interest.

\section{REFERENCES}

1. No authors listed. Chagas disease in Latin America: an epidemiological update based on 2010 estimates. Wkly Epidemiol Rec. 2015;90(6):33-43.

2. WHO Expert Committees. Control of Chagas Disease. http://www. whqlibdoc.who.int/trs/WHO_TRS_905.pdf. 2002 [cited 2020 01/15].

3. Rocha MO, Teixeira MM, Ribeiro AL. An update on the management of Chagas cardiomyopathy. Expert Rev Anti Infect Ther. 2007;5(4):727-43.

4. Botoni FA, Ribeiro AL, Marinho CC, Lima MM, Nunes Mdo C, Rocha MO. Treatment of Chagas cardiomyopathy. Biomed Res Int. 2013:849504.

5. Dias JCP, Ramos Jr. AN, Gontijo ED, Luquetti A, Shikanai-Yasuda MA, Coura JR, et al. 2 nd Brazilian Consensus on Chagas Disease, 2015. Rev Soc Bras Med Trop. 2016;49(Suppl 1):3-60.

6. Nunes MCP, Beaton A, Acquatella H, Bern C, Bolger AF, Echeverria LE, et al. Chagas Cardiomyopathy: An Update of Current Clinical Knowledge and Management: A Scientific Statement From the American Heart Association. Circulation. 2018;138(12):e169-e209.

7. Costa HS, Lima MMO, Costa F, Chaves AT, Nunes MCP, Figueiredo PHS, et al. Reduced functional capacity in patients with Chagas disease: a systematic review with meta-analysis. Rev Soc Bras Med Trop. 2018;51(4):421-6.

8. Costa HS, Nunes MCP, Souza ACd, Lima MMO, Carneiro RB, Sousa GRd, et al. Exercise-induced ventricular arrhythmias and vagal dysfunction in Chagas disease patients with no apparent cardiac involvement. Rev Soc Bras Med Trop. 2015;48(2):175-80.

9. Ribeiro ALP, Rocha MOdC. Forma indeterminada da doença de Chagas: considerações acerca do diagnóstico e do prognóstico. Rev Soc Bras Med Trop. 1998;31(3):301-14.

10. Lang RM, Badano LP, Mor-Avi V, Afilalo J, Armstrong A, Ernande $\mathrm{L}$, et al. Recommendations for cardiac chamber quantification by echocardiography in adults: an update from the American Society of Echocardiography and the European Association of Cardiovascular Imaging. Eur Heart J Cardiovasc Imaging. 2015;16(3):233-70.

11. Guazzi M, Myers J, Abella J, Peberdy MA, Bensimhon D, Chase P, et al. The added prognostic value of ventilatory efficiency to the Weber classification system in patients with heart failure. Int $\mathrm{J}$ Cardiol. 2008;129(1):86-92.

12. Mady C, Cardoso R, Barretto A, da Luz PL, Bellotti G, Pileggi F. Survival and predictors of survival in patients with congestive heart failure due to Chagas' cardiomyopathy. Circulation. 1994;90(6):3098-102.

13. Ritt LE, Carvalho AC, Feitosa GS, Pinho-Filho JA, Andrade MVS, Feitosa-Filho GS, et al. Cardiopulmonary exercise and 6-min walk tests 
as predictors of quality of life and long-term mortality among patients with heart failure due to Chagas disease. Int J Cardiol. 2013;168(4):4584-5.

14. Swank AM, Horton J, Fleg JL, Fonarow GC, Keteyian S, Goldberg L, et al. Modest increase in peak VO2 is related to better clinical outcomes in chronic heart failure patients: results from heart failure and a controlled trial to investigate outcomes of exercise training. Circ Heart Fail. 2012;5(5):579-85.

15. Guazzi M, Bandera F, Ozemek C, Systrom D, Arena R. Cardiopulmonary exercise testing: what is its value? J Am Coll Cardiol. 2017;70(13):161836.

16. Weber KT, Kinasewitz GT, Janicki JS, Fishman AP. Oxygen utilization and ventilation during exercise in patients with chronic cardiac failure. Circulation. 1982;65(6):1213-23.

17. Balady GJ, Arena R, Sietsema K, Myers J, Coke L, Fletcher GF, et al. Clinician's Guide to cardiopulmonary exercise testing in adults: a scientific statement from the American Heart Association. Circulation. 2010;122(2):191-225.

18. Pedrosa RC, Melo MFV, Saad EA. Limiar anaeróbio detectado pela "análise da curva-V" na cardiopatia chagásica crônica. Rev Soc Bras Med Trop. 1997;30(2):129-38.

19. Arena R, Myers J, Williams MA, Gulati M, Kligfield P, Balady GJ, et al. Assessment of functional capacity in clinical and research settings: a scientific statement from the American Heart Association Committee on Exercise, Rehabilitation, and Prevention of the Council on Clinical Cardiology and the Council on Cardiovascular Nursing. Circulation. 2007;116(3):329-43.

20. Pedrosa RC, Salles JHG, Magnanini MM, Bezerra DC, Bloch KV. Prognostic Value of Exercise-Induced Ventricular Arrhythmia in Chagas' Heart Disease. Pacing Clin Electrophysiol. 2011;34(11):1492-7.

21. Rocha ALL, Rocha MOdC, Teixeira BOS, Lombardi F, Abreu CDG, Bittencourt RJ, et al. Índice cronotrópico-metabólico na doença de Chagas. Rev Soc Bras Med Trop. 2005;38(5):373-6.

22. Mady C, Junior PY, Barreto ACP, Saraiva JF, Vianna CdB, Azul LGdS, et al. Estudo da capacidade funcional máxima pela ergoespirometria em pacientes portadores da doença de Chagas. Arq Bras Cardiol. 1986;47(3):201-5

23. Costa HS, Lima MM, de Sousa GR, de Souza AC, Alencar MC, Nunes $\mathrm{MC}$, et al. Functional capacity and risk stratification by the Six-minute Walk Test in Chagas heart disease: comparison with Cardiopulmonary Exercise Testing. Int J Cardiol. 2014;177(2):661-3.

24. Alvarenga JCd, Jansen PD, Marques VEG, Costa HS, Sousa GRd, Souza $\mathrm{ACd}$, et al. Relação entre a fração de ejeção do ventrículo esquerdo e razão e/e' com a capacidade funcional na cardiopatia chagásica. Rev Assoc Med Minas Gerais. 2014;24(Sup1 9):S20-S5.

25. Lima MM, Nunes MC, Rocha MO, Beloti FR, Alencar MC, Ribeiro AL. Left ventricular diastolic function and exercise capacity in patients with Chagas cardiomyopathy. Echocardiography. 2010;27(5):519-24.

26. Costa HS, Lima MM, Alencar MC, Sousa GR, Figueiredo PH, Nunes MC, et al. Prediction of peak oxygen uptake in patients with Chagas heart disease: Value of the Six-minute Walk Test. Int J Cardiol. 2017;228:385-7.

27. Nunes Mdo C, Beloti FR, Lima MM, Barbosa MM, Pinto Filho MM, de Barros MV, et al. Functional capacity and right ventricular function in patients with Chagas heart disease. Eur J Echocardiogr. 2010;11(7):590-5.

28. Costa HS, Lima MMO, Nunes MCP, Sousa GR, Almeida FRd, Figueiredo PHS, et al. Inspiratory muscle weakness in patients with Chagas heart disease: Echocardiographic and functional predictors. IJC Metab Endocr. 2017;14:21-5.
29. Arena R, Myers J, Aslam SS, Varughese EB, Peberdy MA. Peak $\mathrm{VO} 2$ and $\mathrm{VE} / \mathrm{VCO} 2$ slope in patients with heart failure: a prognostic comparison. Am Heart J. 2004;147(2):354-60.

30. Arena R, Myers J, Guazzi M. The clinical importance of cardiopulmonary exercise testing and aerobic training in patients with heart failure. Braz J Phys Ther. 2008;12(2):75-87.

31. Poggio R, Arazi HC, Giorgi M, Miriuka SG. Prediction of severe cardiovascular events by $\mathrm{VE} / \mathrm{VCO} 2$ slope versus peak $\mathrm{VO} 2$ in systolic heart failure: a meta-analysis of the published literature. Am Heart J. 2010;160(6):1004-14.

32. Sarullo FM, Fazio G, Brusca I, Fasullo S, Paterna S, Licata P, et al. Cardiopulmonary Exercise Testing in Patients with Chronic Heart Failure: Prognostic Comparison from Peak VO2 and VE/VCO2 Slope. Open Cardiovasc Med J. 2010;4:127-34.

33. Pedrosa RC, Campos MCd. Teste ergométrico e o Holter de 24 horas na detecção de arritmias ventriculares complexas em diferentes estádios da cardiopatia chagásica crônica. Rev Soc Bras Med Trop. 2004;37(5):37683.

34. Mady C, Ianni BM, Arteaga E, Salemi VM, de Carvalho Frimm C. Maximal functional capacity in patients with Chagas' cardiomyopathy without congestive heart failure. J Card Fail. 2000;6(3):220-4.

35. Higuchi Mde L, Benvenuti LA, Martins Reis M, Metzger M. Pathophysiology of the heart in Chagas' disease: current status and new developments. Cardiovasc Res. 2003 15;60(1):96-107.

36. Van de Veire NR, De Winter O, Philippe J, De Buyzere M, Bernard D, Langlois M, et al. Maximum oxygen uptake at peak exercise in elderly patients with coronary artery disease and preserved left ventricular function: the role of inflammation on top of tissue Doppler-derived systolic and diastolic function. Am Heart J. 2006;152(2):297 e1-7.

37. Grewal J, McCully RB, Kane GC, Lam C, Pellikka PA. Left ventricular function and exercise capacity. JAMA. 2009 21;301(3):286-94.

38. Di Salvo TG, Mathier M, Semigran MJ, Dec GW. Preserved right ventricular ejection fraction predicts exercise capacity and survival in advanced heart failure. J Am Coll Cardiol. 1995;25(5):1143-53.

39. Costa HS, Lima MMO, Figueiredo PHS, Chaves AT, Nunes MCP, da Costa Rocha MO. The prognostic value of health-related quality of life in patients with Chagas heart disease. Qual Life Res. 2019;28(1):67-72.

40. Costa HS, Lima MMO, Figueiredo PHS, Martinelli PM, Camargos ER, Chaves AT, et al. Prognostic value of serum brain-derived neurotrophic factor levels in patients with Chagas cardiomyopathy. Mem Inst Oswaldo Cruz. 2018;113(10):e180224

41. Silva RRD, Reis MS, Pereira BB, Nascimento EMD, Pedrosa RC. Additional value of anaerobic threshold in a general mortality prediction model in a urban patient cohort with Chagas cardiomyopathy. Rev Port Cardiol. 2017;36(12):927-34.

42. Souza FCdCe, Lorenzo AD, Serra SM, Colafranceschi AS. Avaliação do Prognóstico na Cardiomiopatia Chagásica através do Teste Cardiopulmonar de Exercício. Int J Cardiovasc Sci. 2015;28(6):440-50.

43. de Paola AA, Gomes JA, Terzian AB, Miyamoto MH, Martinez Fo EE. Ventricular tachycardia during exercise testing as a predictor of sudden death in patients with chronic chagasic cardiomyopathy and ventricular arrhythmias. Br Heart J. 1995;74(3):293-5.

44. Pedrosa RC, Salles JH, Magnanini MM, Bezerra DC, Bloch KV. Prognostic value of exercise-induced ventricular arrhythmia in Chagas' heart disease. Pacing Clin Electrophysiol. 2011;34(11):1492-7.

45. Giannitsi S, Bougiakli M, Bechlioulis A, Kotsia A, Michalis LK, Naka KK. 6-minute walking test: a useful tool in the management of heart failure patients. Ther Adv Cardiovasc Dis. 2019;13:1753944719870084. 
46. ATS. ATS statement: guidelines for the six-minute walk test. Am J Respir Crit Care Med. 2002;166(1):111-7.

47. Morales FJ, Montemayor T, Martinez A. Shuttle versus six-minute walk test in the prediction of outcome in chronic heart failure. Int $\mathrm{J}$ Cardiol. 2000;76(2-3):101-5.

48. Singh SJ, Morgan MD, Scott S, Walters D, Hardman AE. Development of a shuttle walking test of disability in patients with chronic airways obstruction. Thorax. 1992;47(12):1019-24.

49. Costa HS, Lima MMO, Lage SM, da Costa FSM, Figueiredo PHS, da Costa Rocha MO. Six-minute walk test and incremental shuttle walk test in the evaluation of functional capacity in Chagas heart disease. J Exerc Rehabil. 2018;14(5):844-50.

50. Sousa L, Botoni FA, Britto RR, Rocha MO, Teixeira AL, Jr., Teixeira $\mathrm{MM}$, et al. Six-minute walk test in Chagas cardiomyopathy. Int $\mathrm{J}$ Cardiol. 2008;125(1):139-41.

51. Dourado KCC, Bestetti RB, Cardinalli-Neto A, Cordeiro JA. Evaluation of the six-minute walk test in patients with chronic heart failure associated with Chagas' disease and systemic arterial hypertension. Rev Soc Bras Med Trop. 2010;43(4):405-8.

52. Vieira FC, de Melo Marinho PE, Brandao DC, Barbosae e Silva O. Respiratory muscle strength, the six-minute walk test and quality of life in Chagas cardiomyopathy. Physiother Res Int. 2014;19(1):8-15.

53. Chambela MC, Mediano MFF, Ferreira RR, Japiassu AM, Waghabi MC, da Silva GMS, et al. Correlation of 6-min walk test with left ventricular function and quality of life in heart failure due to Chagas disease. Trop Med Int Health. 2017;22(10):1314-21.

54. Costa SdA, Rassi S, Freitas EMdM, Gutierrez NdS, Boaventura FM, Sampaio LPdC, et al. Prognostic Factors in Severe Chagasic Heart Failure. Arq Bras Cardiol. 2017;108(3):246-54.

55. Alves R, Lima MM, Fonseca C, Dos Reis R, Figueiredo PH, Costa H, et al. Peak oxygen uptake during the incremental shuttle walk test in a predominantly female population with Chagas heart disease. Eur J Phys Rehabil Med. 2016;52(1):20-7.

56. Costa HS, Alves RL, da Silva SA, Alencar MC, Nunes Mdo C, Lima MM, et al. Assessment of Functional Capacity in Chagas Heart Disease by Incremental Shuttle Walk Test and its Relation to Quality-of-Life. Int J Prev Med. 2014;5(2):152-8.

57. Martins-Melo FR, Carneiro M, Ribeiro ALP, Bezerra JMT, Werneck GL. Burden of Chagas disease in Brazil, 1990-2016: findings from the Global Burden of Disease Study 2016. Int J Parasitol. 2019;49(3-4):301-10.

58. Ribeiro AL, Nunes MP, Teixeira MM, Rocha MO. Diagnosis and management of Chagas disease and cardiomyopathy. Nat Rev Cardiol. 2012;9(10):576-89.

59. Ribeiro ALP. Functional capacity in Chagas disease. Rev Soc Bras Med Trop. 2018;51(4):413-4.

60. Andrade JPd, Marin Neto JA, Paola AAVd, Vilas-Boas F, Oliveira GMM, Bacal F, et al. I Diretriz Latino-Americana para o diagnóstico e tratamento da cardiopatia chagásica: resumo executivo. Arq Bras Cardiol. 2011;96(6):434-42.

61. Alves RMdA, Thomaz RP, Almeida EAd, Wanderley JdS, Guariento ME. Chagas' disease and ageing: the coexistence of other chronic diseases with Chagas' disease in elderly patients. Rev Soc Bras Med Trop. 2009;42(6):622-8.

62. Almeida EAd, Barbosa Neto RM, Guariento ME, Wanderley JdS, Souza MLd. Apresentação clínica da doença de Chagas crônica em indivíduos idosos. Rev Soc Bras Med Trop. 2007;40(3):311-5.

63. Vizzoni AG, Varela MC, Sangenis LHC, Hasslocher-Moreno AM, do Brasil P, Saraiva RM. Ageing with Chagas disease: an overview of an urban Brazilian cohort in Rio de Janeiro. Parasit Vectors. 2018;11(1):354.

64. Rocha MOC, Correia PC, Barros MVL, Torres RM, Ribeiro ALP, Teixeira MM. Cardiovascular function in elderly patients with chronic chagasic cardiopathy. Rev Soc Bras Med Trop. 2003;36(5):545-50. 